\title{
Clinical and laboratory analysis of late-onset glutaric aciduria type I (GA-I) in Uighur: A report of two cases
}

\author{
XIAOYING ZHANG and QIONG LUO
}

Department of Pediatrics, The First Affiliated Hospital of Xinjiang Medical University, Urumqi, Xinjiang 830054, P.R. China

Received August 19, 2015; Accepted October 5, 2016

DOI: $10.3892 /$ etm.2016.4007

\begin{abstract}
The aim of the present study was to investigate the clinical, biochemical and genetic mutation characteristics of two cases of late-onset glutaric aciduria type I (GA-I) in Uighur. The clinical data and glutaryl-CoA dehydrogenase (GCDH) genetic test results of two cases of late-onset GA-I in Uighur were collected and analyzed, and reviewed with relevant literature. One patient with late-onset GA-I primarily exhibited clinical intermittent headache, while the other patient was asymptomatic. The urinary organic acid analysis detected a large number of glutaric acid and 3-hydroxy glutaric acid, 3-hydroxy-propionic acid. One patient exhibited white matter degeneration in cranial magnetic resonance imaging (MRI) and the other patient showed no abnormality. The two patients both exhibited c. 1204C >T, p.R402W, heterozygous mutation, and c. $532 \mathrm{G}>\mathrm{A}$, p.G178R, heterozygous mutation. Besides central nervous system infectious diseases, patients with clinical headache, cranial MRI-suggested bilateral temporal lobe arachnoid cyst and abnormal signals in the basal ganglia should be highly suspected as late-onset GA-I. Early diagnosis and correct treatment are key to improve its prognosis.
\end{abstract}

\section{Introduction}

Glutaric aciduria type I (GA-I) is a rare autosomal recessive disease with abnormalities in organic acid metabolism, and is caused by the functional defects of glutaryl-CoA dehydrogenase $(\mathrm{GCDH})$, which results in metabolic disorders of lysine, hydroxylysine and tryptophan, leading to the excessive accumulation of bypass metabolites, such as glutaric acid, 3-hydroxy-glutaric acid and other toxic substances. This results in an increase in urine levels of glutaric acid and 3-hydroxy-glutaric acid (1). It has been reported that the

Correspondence to: Professor Xiaoying Zhang, Department of Pediatrics, The First Affiliated Hospital of Xinjiang Medical University, 137 Liyushannan Road, Urumqi, Xinjiang 830054, P.R. China

E-mail: xiaoyingzhangcn@126.com

Key words: glutaric aciduria type I, glutaryl coenzyme A dehydrogenase, $G C D H$ gene, Uighur incidence rate of GA-I is 1:100,000 (2). Approximately $90 \%$ of patients develop GA-I in early childhood, and the remaining $10 \%$ of patients show mild symptoms or no symptoms (3). In recent years, GA-I in the Chinese population has gained increasing interest (4-7). However, a large number of children do not receive a timely diagnosis and proper treatment clinically. In particular, no research about GA-I in Uighur has been reported. Therefore, further research is required in order to determine the incidence of GA-I in Chinese children. The present study collected and analyzed the clinical, biochemical, neuroimaging and genetic mutation information of two patients with GA-I in one Uighur family, admitted to the Department of Pediatrics, The First Hospital of Xinjiang Medical University (Urumqi, China) in 2014. The study was conducted in accordance with the declaration of Helsinki, and received approval from the Ethics Committee of Xinjiang Medical University. Written informed consent was obtained from all participants.

\section{Case reports}

Case 1. A 12-year-old Uighur girl from Xinjiang, China, was admitted to the Department of Pediatrics, The First Affiliated Hospital of Xinjiang Medical University in October 2014 for an intermittent headache (0.5-2 h in duration) over a period of 2 months. The headache typically occurred once every 3-5 days, with no increasing or decreasing trend. The patient reported no other particular discomfort. Hospital examination revealed that blood glucose, creatine kinase, blood lactate and alanine transaminase levels were within normal ranges. Outpatient cranial magnetic resonance imaging (MRI) revealed white matter degeneration. As a result, a diagnosis of encephalitis or inherited metabolic disease was considered.

Regarding previous disease history, the patient exhibited normal growth and development, intelligence, vision and hearing, but exhibited poor physical strength and endurance since childhood, could not tolerate hunger, and had no particular bad habits. The patient was from a non-consanguineous marriage.

On physical examination, the patient had a clear mind, symmetrical body and no weight loss. Cheek skin exhibited a scattered red rash, and cranial nerve examination revealed no abnormalities. The muscle strength of the bi-upper and bi-lower limbs was grade 5 in the MRC scale (8); the muscle tonus of the four limbs was normal, with normal tendon reflexes in the upper and lower limbs. No bilateral pathological signs were 
detected, and the body's superficial sensation examinations were normal. The finger-to-nose test was normal, with no meningeal irritation.

Cranial MRI showed bilateral temporal lobe arachnoid cyst, focal patchy $\mathrm{T} 2$ flair high signals in semi-oval area, corner and anteroposterior horns of the lateral ventricle, indicating white matter degeneration (Figs. 1 and 2). The figures were captured at two month intervals, and no significant change was identified.

Case 2. A 6-year-old Uighur girl from Xinjiang was the sister of case 1 , and presented with no clinical symptoms. Physical examination and imaging tests showed no abnormalities.

Laboratory tests and diagnosis. Tandem mass spectrometry (MS/MS) and gas chromatography/mass spectrometry (GC/MS) were used to analyze blood acylcarnitine and urine organic acids in the patient with suspected GA-I. To detect blood acylcarnitine and amino acids by MS/MS, venous blood was sampled, dripped onto special filter paper, and sent for detection after drying. An MS/MS instrument (API 2,000; Applied Biosystems; Thermo Fisher Scientific, Inc., Waltham, MA, USA) was used for the testing. For the detection of organic acids by GC/MS, urine samples were treated with urease, hydrochloric acid hydroxylammonium, sodium hydroxide and hydrochloric acid, and a GC/MS instrument (QP2010; Shimadzu Corporation, Kyoto, Japan) for detection.

The results of MS/MS and GC/MS detection are presented in Tables I-III. Urinary glutaric acid and 3-hydroxy-glutaric acid in the two patients were increased, and glutaric acid levels were increased by 2,510.08- and 1,172.28-fold compared with the normal reference value (0-4), in cases 1 and 2 , respectively. Levels of 3-hydroxy glutaric acid were increased by 22.58- and 12.19-fold compared with the normal reference value (0) (Tables I and II) in cases 1 and 2, respectively. Blood acylcarnitine analysis showed that glutaryl carnitine in the cases 1 and 2 was increased by 0.8 and $1.177 \mu \mathrm{mol} \cdot 1^{-1}$, respectively (normal reference value, $0-0.20 \mu \mathrm{mol}^{-1}{ }^{-1}$ ), while free acylcarnitine in the two patients was markedly reduced by 7.887 and $6.011 \mu \mathrm{mol} \cdot \mathrm{l}^{-1}$, respectively (normal reference value, 10-60 $\mu \mathrm{mol} \cdot \mathrm{l}^{-1}$ ) (Table III). The above manifestations were in line with the diagnosis of GA-I.

Genetic results of the two patients are presented in Table IV. The test results of arylsulfatase A and galactocerebroside esterase of cases 1 and 2 were both within the normal ranges, 170.8 and $31.0 \mathrm{nmol} / 17 \mathrm{~h} / \mathrm{mgPr} ; 152.4$ and $27.6 \mathrm{nmol} / 17 \mathrm{~h} / \mathrm{mgPr}$, respectively (reference values, 134.1-325.1 nmol/17 h/mgPr and 19.0-68.2 nmol/17 h/mgPr, respectively). As a result, a diagnosis of leukodystrophy could be excluded (Table IV).

Genetic analysis of GCDH in the two patients and their parents was performed by gene DNA sequencing. Polymerase chain reaction amplified all exons and para-intronic regions of GCDH, and a DNA automatic analyzer was used to analyze the amplification products. Two mutations were detected in the patients: Loci c. $1204 \mathrm{C}>\mathrm{T}$, p.R402W, heterozygous mutation, originating from the father; and c. 532G >A, p.G178R, heterozygous mutation, originating from the mother. These two mutations had been previously reported, and were considered as the pathogenic mutations $(9,10)$.
Electromyography showed no abnormalities in any muscles (bi-rectus femoris and bi-gastrocnemius). In conclusion, a diagnosis of late-onset GA-I was decided for both cases.

Treatment and follow-up. After the diagnosis of GA-I was confirmed by MS, no muscle biopsy was performed according to patients' wishes. The patients were administered a low-fat, low-protein and high-carbohydrate diet, and large doses of vitamin B2 (50 mg, tid) and L-carnitine $(100 \mathrm{mg} / \mathrm{kg} / \mathrm{day})$ were supplemented for symptomatic treatment. The headache symptom in case 1 disappeared, and follow-up review showed that lactic acid, enzymes and liver functions were all within normal ranges. The follow-up was lasted for two months, and the patients expressed no clinical symptoms within that period.

\section{Discussion}

GA-I is a relatively rare disease among organic aciduria that was first reported in 1975 by Goodman (11), and >200 pathogenic mutations have been reported to date (12). The incidence rates of GA-I vary between different races, and it has been reported as $\sim 1 / 60,000$ individuals in China (13). To date, there are no reports of GA-I in Uighur children. GA-I typically induces acute encephalopathic crisis within 3 to 36 months of delivery, due to non-specific factors, such as infection, fever and vaccinations. These typically result in induced striatal neuron degeneration, and often result in severe neurological sequela, such as dystonia and extrapyramidal symptoms (14). An early diagnosis, together with a reasonable diet, energy supplements and active treatment towards complicating diseases (such as induced acute encephalopathy) could significantly improve the prognosis; however, nearly one-third of pediatric patients experiencing GA-I suffer from severe neurological sequela even after aggressive treatment (15).

Patients with incubative disease would exhibit no acute encephalopathic crisis, but would experience gradually progressive nervous system damage (16). Currently, pathogenesis study of GA-I typically focusses on the selective accumulation mechanisms of GA, other metabolites in the brain, and the neurotoxic mechanisms of GA and other metabolites (17). The abnormal increasing of GA, 3-hydroxyglutaric acid and other metabolites in the brain might cause striatal neuronal degeneration, wide white matter degeneration and gliosis. The abnormal accumulation of metabolites would cause excitatory damage, energy metabolism damage and oxidative stress. In addition, other risk factors, such as glial activation, vascular injury, inflammatory factors and other causative factors, are involved in collaborative neurotoxic damage (18).

In the present study, case 1 exhibited neurological symptoms during treatment, with an onset age of 12 years. The patient lacked specific clinical symptoms, and lesions were only identified after completing a brain MRI. Following the MRI, the patient's family members were recommended for blood acylcarnitine and urine organic acid analysis. The results showed that the patient's sister (case 2) also had late-onset GA-I, but experienced no clinical symptoms or signs. Macrocephaly is a typical characteristic of GA-I (14), but this characteristic did not appear in either cases 1 or 2 . Early onset GA-I commonly exhibits hypoevolutism or reverse development, muscle tonus disorder and seizure, and nearly 

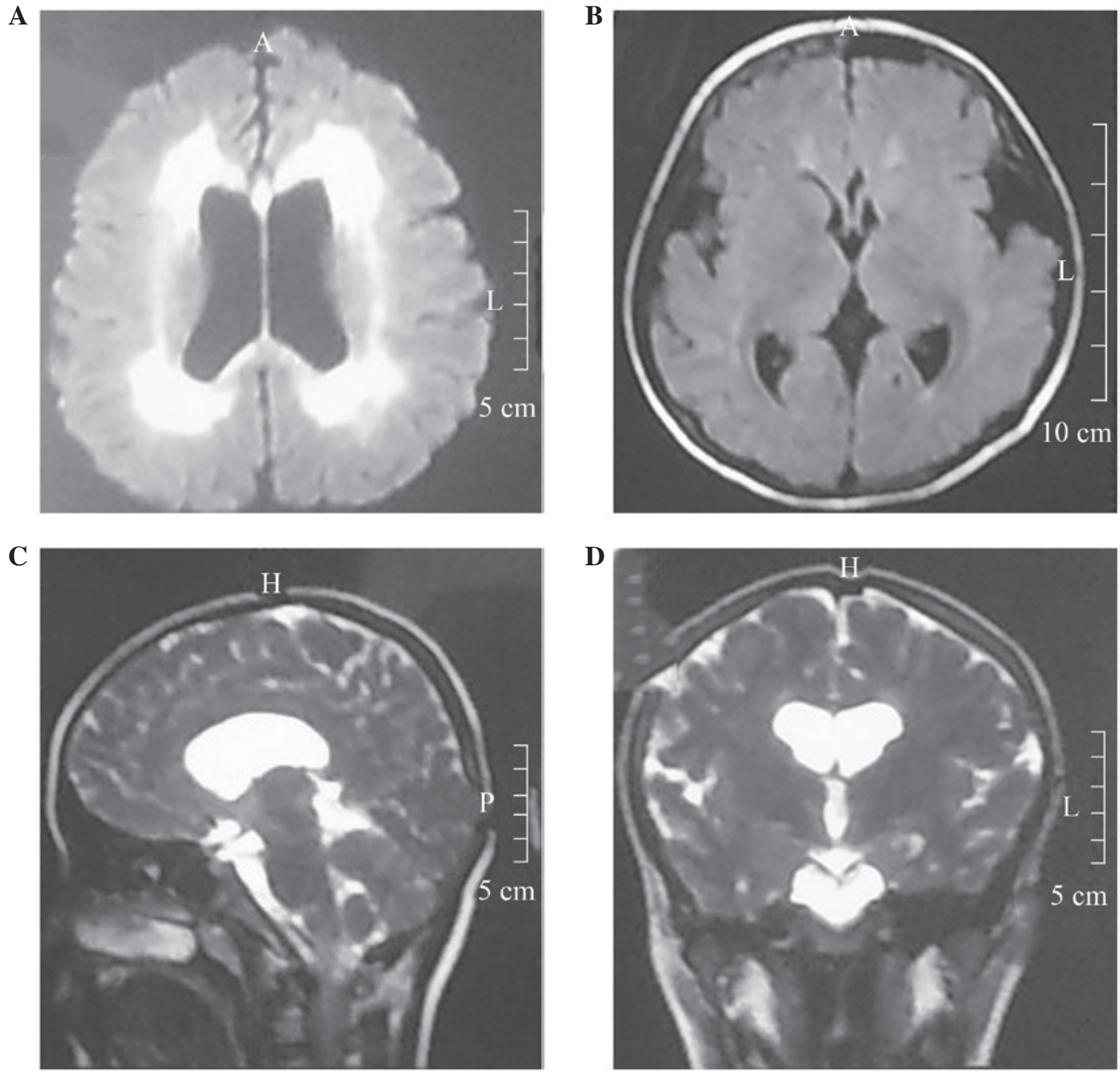

Figure 1. November 13, 2014, focal patchy T2 flair high signals of the bilateral temporal tip arachnoid cyst, semi-oval area and anteroposterior horns of the lateral ventricles (case 1). (A) The white matter around the lateral ventricle shows markedly increased signal in the diffuse-weighted image. (B) The bilateral fissure cisterns are widened, especially on the left side in the T2 Flair image. (C) The ventricle expands in the sagittal T2 image, and exhibits mild dropsy. (D) the lateral ventricle expands in the coronal T2 image.

half of patients exhibit acute neurological degeneration when under stress (19). The symptoms of late-onset GA-I are relatively mild, with primary clinical manifestations of motion retrogression and paroxysmal headache, which typically develop premorbidly. Patients usually have a relatively good prognosis and fast recovery, and their intelligence and motion abilities can resume to normal, suggesting that the age of onset is associated with clinical prognosis (20). In the present study, case 1 exhibited headache with normal cognitive functions, and cranial MRI exhibited focal patchy T2 flair high signals in the semi-oval area, corner and anteroposterior horns of te lateral ventricle. The clinical symptoms disappeared after treatment, while cranial MRI exhibited no significant changes, consistent with previously reported literature $(21,22)$.

Achieving a clinical diagnosis of GA-I is difficult, and urine organic acid analysis is the key technology in screening and diagnosing GA-I. However, diagnostic screening could rely on GC/MS technology to analyze the levels of urine glutaric acid and 3-hydroxy-glutaric acid and MS/MS technology could be used to analyze the level of acetylcarnitine in blood. In addition, GCDH activity detection or gene testing can be used to diagnose GA-I $(23,24)$. In the present study, the two cases were confirmed because of the markedly increased concentrations of urine glutaric acid and 3-hydroxy-glutaric acid. The results from these two patients showed that glutaryl carnitine was increased, while free carnitine was reduced; therefore, it is recommended the suspected GA-I patients should undergo urine organic acid analysis, the blood acylcarnitine ester spectrum should be monitored in order to confirm diagnosis.

GCDH is a key enzyme in the catabolic pathways of tryptophan, lysine and hydroxylysine, and can catalyze the oxidative decarboxylation of glutaryl coenzyme A, generate crotonyl coenzyme $\mathrm{A}$ and $\mathrm{CO}_{2}$; the gene for this enzyme was located at $19 \mathrm{p} 13.2$, which is associated with $>200$ types of pathogenic mutations (12). Different mutations result in different degrees of enzyme deficiency, and the residual enzyme activity is associated with a patient's biochemical phenotype (urinary GA content), but is not associated with clinical phenotype (12). The analysis of GCDH mutation could further confirm the disease, thus guiding the genetic counseling of patients' family members and the prenatal diagnosis of the next child. There may exist differences of 
Table I. Gas chromatography/mass spectrometry results of urine in case 1.

\begin{tabular}{rlcccccc}
\hline No. & Test item & Results & $\begin{array}{c}\text { Normal } \\
\text { average }\end{array}$ & $\begin{array}{c}\text { Normal } \\
\text { min. }\end{array}$ & $\begin{array}{c}\text { Normal } \\
\text { max. }\end{array}$ & $\begin{array}{c}\text { Results } \\
\text { (average) }\end{array}$ & $\begin{array}{c}\text { Results } \\
\text { (max) }\end{array}$ \\
\hline 1 & Lactic acid-2 21.61 & 0.8 & 0 & 4.7 & 27.01 & 4.60 & \\
2 & 2-hydroxy-isobutyric acid-2 & $5.73^{\mathrm{a}}$ & 0 & 0 & 0 & - & - \\
4 & Glycolic acid-293.59a & 0.7 & 0 & 2.2 & 133.70 & 42.54 & 25.24 \\
8 & 3-hydroxy-propionic acid-2 & $27.76^{\mathrm{a}}$ & 0.2 & 0 & 1.1 & 138.80 & 2.75 \\
12 & 3-hydroxy-isobutyric acid-2 & $24.71^{\mathrm{a}}$ & 2.5 & 0 & 9 & 9.88 & 7.92 \\
16 & 3-hydroxy-isovaleric acid-2- & $18.21^{\mathrm{a}}$ & 0.8 & 0 & 2.3 & 22.76 & 14.53 \\
31 & Glycerol-3-keto-isocaproic acid-OX-2 & $11.62^{\mathrm{a}}$ & 0.3 & 0 & 0.8 & 38.73 & -41.15 \\
48 & Isobutyryl-glycine-1 & $16.46^{\mathrm{a}}$ & 0 & 0 & 0.4 & $2,510.08$ & - \\
51 & Glutaric aicd-24,769.16 & 0 & 0 & 4 & 22.14 & $1,192.29$ & - \\
55 & Propionyl glycine-2 & $83.55^{\mathrm{a}}$ & & 0 & 0 & - & - \\
60 & Glutaconic acid-25.74 & 0 & 0 & 0 & - & - & - \\
81 & 2-hydroxy-glutaric acid-3 & $50.93^{\mathrm{a}}$ & 2.3 & 0.6 & 5.9 & - & -6.63 \\
82 & 3-hydroxy glutaric aicd & $22.58^{\mathrm{a}}$ & 0 & 0 & 0 & - & 19.48 \\
86 & 3-hydroxy-phenylacetic acid-2- & $17.53^{\mathrm{a}}$ & 0.4 & 0 & 0.9 & 43.83 & \\
123 & Palmitic acid-1 98.61 & 6 & 0 & 13.8 & 16.44 & 7.15 & \\
130 & 3,6-epoxy-dodecanedioic acid -2 & $9.84^{\mathrm{a}}$ & 1.6 & 0 & 5.2 & 6.15 & 1.89 \\
\hline
\end{tabular}

${ }^{\mathrm{a}}$ Abnormal.

A

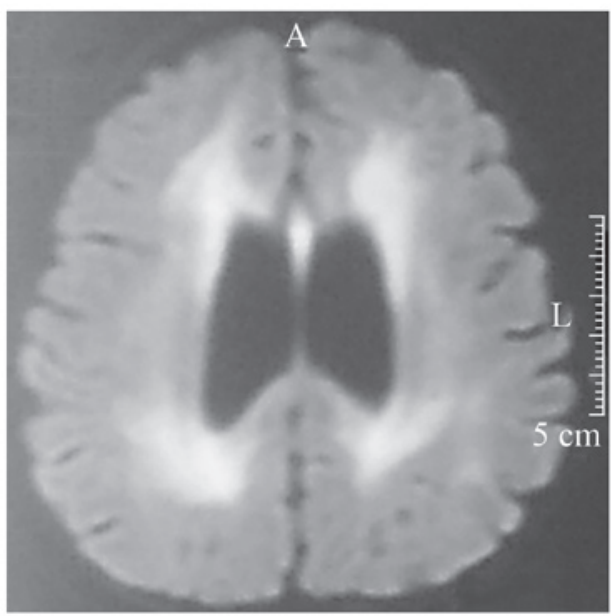

C

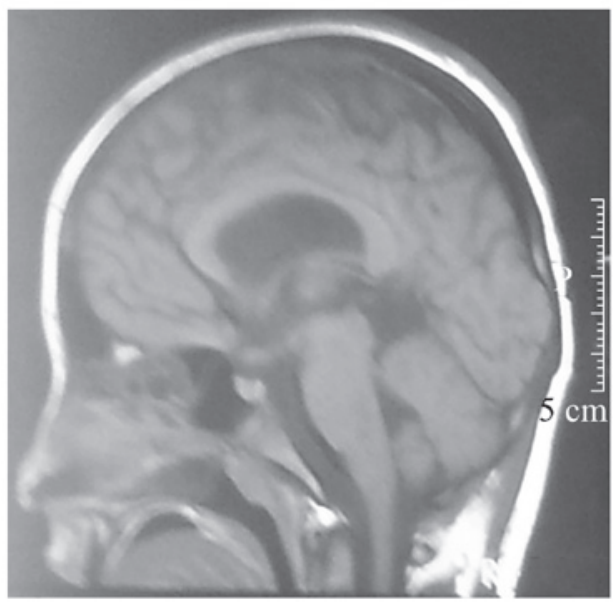

B

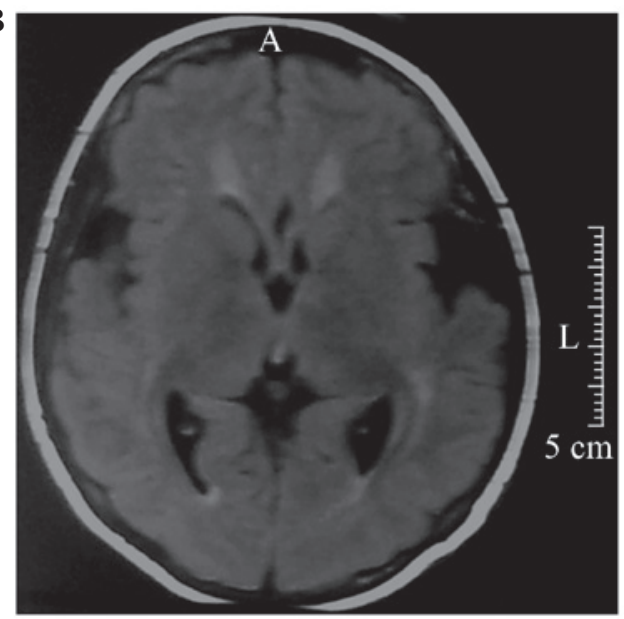

D

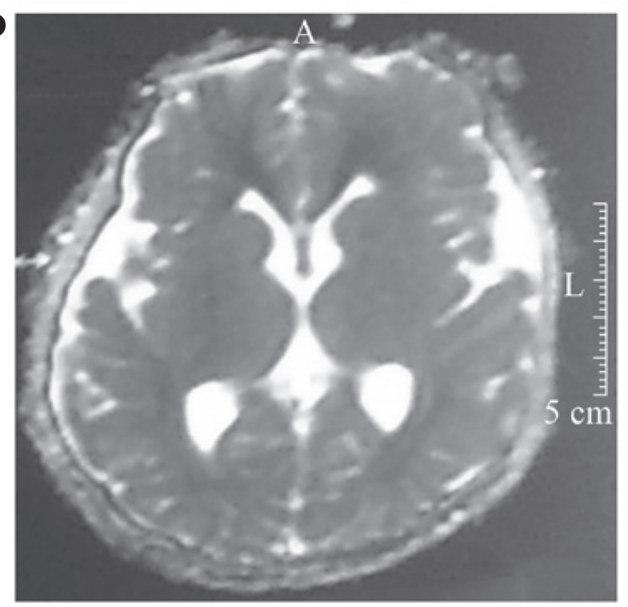

Figure 2. January 20,2015, focal patchy T2 flair high signals of the bilateral temporal tip arachnoid cyst, semi-oval area and anteroposterior horns of the lateral ventricles. (A) The white matter around the lateral ventricle shows markedly increased signal in the diffuse-weighted image. (B) The bilateral fissure cisterns are widened, especially on the left side in the T2 Flair image. (C) The lateral ventricle expands in the sagittal T1 image, and the corpora quadrigemina has expanded slightly. (D) The white matter at the forefoot of lateral ventricle shows a low signal in the ADC image, and the lateral fissure cistern widens. 
Table II. Gas chromatography/mass spectrometry results of urine in case 2.

\begin{tabular}{|c|c|c|c|c|c|c|c|}
\hline No. & Test item & Results & $\begin{array}{l}\text { Normal } \\
\text { average }\end{array}$ & $\begin{array}{c}\text { Normal } \\
\text { min. }\end{array}$ & $\begin{array}{c}\text { Normal } \\
\max .\end{array}$ & $\begin{array}{l}\text { Results } \\
\text { (average) }\end{array}$ & $\begin{array}{c}\text { Results } \\
\text { (max.) }\end{array}$ \\
\hline 2 & 2-hydroxy-isobutyric acid-2 & $3.21^{\mathrm{a}}$ & 0 & 0 & 0 & - & - \\
\hline 4 & Glycolic acid-2 & $12.23^{\mathrm{a}}$ & 0.7 & 0 & 2.2 & 17.47 & 5.56 \\
\hline 8 & 3-hydroxy-propionic acid-2 & $6.96^{\mathrm{a}}$ & 0.2 & 0 & 1.1 & 34.80 & 6.33 \\
\hline 32 & Phosphoric acid-3 & $93.47^{\mathrm{a}}$ & 6.6 & 0 & 43 & 14.16 & 2.17 \\
\hline 48 & Isobutyryl-glycine-1 & $9.84^{\mathrm{a}}$ & 0 & 0 & 0 & - & - \\
\hline 51 & Glutaric acid-2 & $2,227.34^{\mathrm{a}}$ & 1.9 & 0 & 4 & $1,172.28$ & 556.84 \\
\hline 55 & Propionyl glycine-2 & $42.86^{\mathrm{a}}$ & 0 & 0 & 0.4 & - & - \\
\hline 76 & 5-hydroxy-methyl-2-pyromucic acid-1 & $10.73^{\mathrm{a}}$ & 0 & 0 & 0.4 & - & - \\
\hline 81 & 2-hydroxy-glutaric acid-3 & $22.09^{\mathrm{a}}$ & 2.3 & 0.6 & 5.9 & 9.6 & 3.74 \\
\hline 82 & 3-hydroxy glutaric acid & $12.19^{\mathrm{a}}$ & 0 & 0 & 0 & - & - \\
\hline 86 & 3-hydroxyphenylacetic acid-2 & $4.14^{\mathrm{a}}$ & 0.4 & 0 & 0.9 & 10.35 & 4.60 \\
\hline 90 & 2-oxoglutaric acid -OX-2 (2) & $38.19^{\mathrm{a}}$ & 3.5 & 0.3 & 21.3 & 10.91 & 1.79 \\
\hline 123 & Palmitic acid-1 & $77.17^{\mathrm{a}}$ & 6 & 0 & 13.8 & 12.86 & 5.59 \\
\hline 130 & 3,6-epoxy-dodecanedioic acid-2 & $11.21^{\mathrm{a}}$ & 1.6 & 0 & 5.2 & 7.01 & 2.16 \\
\hline
\end{tabular}

${ }^{\mathrm{a} A b n o r m a l}$.

Table III. Plasma acylcarnitine profile measured using tandem mass spectrometry in cases 1 and 2.

\begin{tabular}{lccc}
\hline Detection & $\begin{array}{c}\text { Case 1 } \\
\left(\mu \text { mol. } 1^{-1}\right)\end{array}$ & $\begin{array}{c}\text { Case 2 } \\
\left(\mu \mathrm{mol.1}^{-1}\right)\end{array}$ & $\begin{array}{c}\text { Reference range } \\
\left(\mu \mathrm{mol}^{-1}\right)\end{array}$ \\
\hline Free carnitine (C0) & $7.887^{\mathrm{a}}$ & $6.011^{\mathrm{a}}$ & $10-60$ \\
Isovaleryl carnitine (C5) & $0.051^{\mathrm{a}}$ & $0.058^{\mathrm{a}}$ & $0.04-0.3$ \\
HMG-carnitine (C5DC) & 0.81 & $1.177^{\mathrm{a}}$ & $0-0.2$ \\
Octadecene acyl carnitine (C18DC) & $0.191^{\mathrm{a}}$ & $0.209^{\mathrm{a}}$ & $0.3-1.8$ \\
C5DC/C3 & $1.235^{\mathrm{a}}$ & $2.367^{\mathrm{a}}$ & 0.0 .2 \\
C5DC/C8 & $36.175^{\mathrm{a}}$ & $26.515^{\mathrm{a}}$ & $0.1-2.5$ \\
C5DC/C16 & $2.109^{\mathrm{a}}$ & $4.042^{\mathrm{a}}$ & $0.01-0.15$ \\
C16-OH/C3 & $0.042^{\mathrm{a}}$ & $0.067^{\mathrm{a}}$ & $0-0.04$ \\
\hline
\end{tabular}

${ }^{\mathrm{a} A b n o r m a l .}$

Table IV. Plasma arylsulfatase A and galactocerebroside esterase profile measured using tandem mass spectrometry in two patients.

\begin{tabular}{|c|c|c|c|}
\hline Detection & Case 1 & Case 2 & Reference range \\
\hline Arylsulfatase A & $170.8 \mathrm{nmol} / 17 \mathrm{~h} / \mathrm{mgPr}$ & $152.4 \mathrm{nmol} / 17 \mathrm{~h} / \mathrm{mgPr}$ & 134.1-325.1 nmol/17 h/mgPr \\
\hline Galactocerebroside esterase & $31.0 \mathrm{nmol} / 17 \mathrm{~h} / \mathrm{mgPr}$ & $27.6 \mathrm{nmol} / 17 \mathrm{~h} / \mathrm{mgPr}$ & $19.0-68.2 \mathrm{nmol} / 17 \mathrm{~h} / \mathrm{mgPr}$ \\
\hline
\end{tabular}

The two enzymes were within normal limits, so leukodystrophy was excluded.

GCDH hotspot mutations among GA-I patients in different races and regions. In Caucasians, c. $1204 \mathrm{C}>\mathrm{T}$ was the most common hotspot mutation (9), while c. $914 \mathrm{C}>\mathrm{T}$ was common in Japanese patients (10). However, there lacks a large-sample study in Asians. The present study diagnosed two patients with GA-I on a genetic level in Uighur, mainland of China, for the first time. Both patients expressed the c. $1204 \mathrm{C}>\mathrm{T}$ missense mutation, and the detection of the GCDH gene mutation in their parents revealed that both parents were carriers of the disease-causing gene, which further suggests that this disease shows features of a typical autosomal recessive inheritance disorder. The two patients in this study had 
blood connections, c. $532 \mathrm{G}>\mathrm{A}$ mutation (from the mother) and c. $1204 \mathrm{C}>\mathrm{T}$ mutation (from the father); c. $532 \mathrm{G}>\mathrm{A}$ has not, to date, been reported in the Chinese population before. Because the two patients with late-onset GA-I were Uighurs, and late-onset cases are easily misdiagnosed clinically, a question arises as to whether c. $532 \mathrm{G}>\mathrm{A}$ was the mutation hotspot of late-onset GA-I. Or, whether the mutation is a hotspot in Uighur individuals; this remains to be investigated in large-sample studies.

Internationally, there are standardized treatments applied to GA-I disease (25). However, the number of diagnosed cases in China is few, and popular treatments include a limiting protein diet (particularly lysine and tryptophan), and supplementation with L-carnitine $100 \mathrm{mg} /(\mathrm{kg} \cdot$ day $)$ and vitamin B2 (200-300 mg/day). During the treatment of cases 1 and 2 in this study, it was observed that the application of the above drugs needed to be gradually increased. During the dose-increasing process, particular attention should be paid towards pediatric patients to ensure that they can tolerate the doses. Regarding the application of vitamin B2, the reported method was much more recommended, namely $10 \mathrm{mg} /(\mathrm{kg} \cdot$ day) (26).

The age of onset, treatment and diet of patients are closely associated with the prognosis of GA-I (27). By performing GC-MS in newborns and high-risk screenings, an increasing number of patients with GA-I could obtain diagnosis in asymptomatic or early stages, so that early treatment can improve their prognosis (15). A region in USA applied GS-MS technology to screen high-risk infants of an Amish family between 1988 and 1994, and several asymptomatic patients were identified (26). Early preventive treatment in these cases ensured that the patients did not experience neurological symptoms. However, $78 \%$ of patients are not clearly diagnosed until striatal necrosis appears, which typically results in poor prognosis and disability (26). Poor prognosis may be associated with diarrhea, intermittent withdrawal of L-carnitine and vitamin B2, diet or improper care. Long term, standard treatment could reduce the occurrence of acute encephalopathy and dyskinesia, while discontinuing the treatment could result in irreversible neurological damage.

The above conclusions indicate that GA-I may be associated with phenylketonuria, which can be easily treated. However, since the incidence of GA-I is markedly lower than phenylketonuria, large studies and screening would be difficult in China at this stage. However, once pediatricians are able to recognize specific clinical manifestations of GA-I, early relevant examinations and treatments can be applied. Uighur account for $>50 \%$ of the total population in Xinjiang, where MS/MS and GC/MS detection has only been performed in the past three years, due to limitations of the economy and cultural background. Therefore, patients with clinical manifestations, such as macrocephaly, infection, dehydration or developmental regression after seizure, cranial MRI showing bilateral temporal lobe arachnoid cyst, abnormal basal ganglia signals, and non-trauma and intracranial infection-related subdural effusion or blood, should be assessed for GA-I, since the early detection of this disease will result in early treatment and an improved prognosis. Including GA-I into newborn screening programs would be an effective method for the early diagnosis of glutaric aciduria, although early treatment may not completely avoid damage to the nervous system, it could reduce neurological complications and save a lot of medical expenses (13).

\section{References}

1. Kölker S, Burgard P, Sauer SW and Okun JG: Current concepts in organic acidurias: Understanding intra- and extracerebral disease manifestation. J Inherit Metab Dis 36: 635-644, 2013

2. Fernández-Lainez C, Aguilar-Lemus JJ, Vela-Amieva M and Ibarra-González I: Tandem mass spectrometry newborn screening for inborn errors of intermediary metabolism: Abnormal profile interpretation. Curr Med Chem 19: 4511-4522, 2012.

3. Fraidakis MJ, Liadinioti C, Stefanis L, Dinopoulos A, Pons R, Papathanassiou M, Garcia-Villoria J and Ribes A: Rare late-onset presentation of glutaric aciduria type $I$ in a 16-year-old woman with a novel GCDH mutation. JIMD Rep 18: 85-92, 2015.

4. Liu XM, Li R, Chen SZ, Sang Y, Chen J and Fan CH: Screening of inherited metabolic disorders in infants with infantile spasms. Cell Biochem Biophys 72: 61-65, 2015.

5. Ma J, Tan L and Chen S: A case of choreoathetosis due to glutaric aciduria type 1. Mov Disord 28: 1808, 2013.

6. Wang Q, Li X, Ding Y, Liu Y, Song J and Yang Y: Clinical and mutational spectra of 23 Chinese patients with glutaric aciduria type 1. Brain Dev 36: 813-822, 2014.

7. Tian F, Fu X, Gao J, Ying Y, Hou L, Liang Y, Ning Q and Luo X: Glutaric acid-mediated apoptosis in primary striatal neurons. Biomed Res Int 2014: 484731, 2014.

8. Kalita J, Misra UK and Bansal R: Central motor conduction studies in patients with Guillain Barre Syndrome. Electromyogr Clin Neurophysiol 41: 243-246, 2001.

9. Al-Shamsi A, Hertecant JL, Al-Hamad S, Souid AK and Al-Jasmi F: Mutation spectrum and birth prevalence of inborn errors of metabolism among Emiratis: A study from Tawam hospital metabolic center, united Arab Emirates. Sultan Qaboos Univ Med J 14: e42-e49, 2014.

10. Georgiou T, Nicolaidou P, Hadjichristou A, Ioannou R, Dionysiou M, Siama E, Chappa G, Anastasiadou V and Drousiotou A: Molecular analysis of Cypriot patients with Glutaric aciduria type I: Identification of two novel mutations. Clin Biochem 47: 1300-1305, 2014.

11. Goodman SI, Markey SP, Moe PG, Miles BS and Teng CC: Glutaric aciduria: A 'new' disorder of amino acid metabolism. Biochem Med 12: 12-21, 1975.

12. Kim HS, Yu HJ, Lee J, Park HD, Kim JH, Shin HJ, Jin DK and Lee M: A Korean patient with glutaric aciduria type 1 with a novel mutation in the glutaryl CoA dehydrogenase gene. Ann Clin Lab Sci 44: 213-216, 2014.

13. Hui J, Tang NL, Li CK, Law LK, To KF, Yau P, Fung SL, Chong JS, Tsung L, Chiang G, et al: Inherited metabolic diseases in the Southern Chinese population: Spectrum of diseases and estimated incidence from recurrent mutations. Pathology 46: 375-382, 2014.

14. Kölker S, Cazorla AG, Valayannopoulos V, Lund AM, Burlina AB, Sykut-Cegielska J, Wijburg FA, Teles EL, Zeman J, Dionisi-Vici C, et al: Erratum to: The phenotypic spectrum of organic acidurias and urea cycle disorders. Part 1: The initial presentation. J Inherit Metab Dis 38: 1155-1156, 2015.

15. Couce ML, López-Suárez O, Bóveda MD, Castiñeiras DE, Cocho JA, García-Villoria J, Castro-Gago M, Fraga JM and Ribes A: Glutaric aciduria type I: Outcome of patients with early-versus late-diagnosis. Eur J Paediatr Neurol 17: 383-389, 2013.

16. Kurtcan S, Aksu B, Alkan A, Guler S and Iscan A: MRS features during encephalopathic crisis period in 11 years old case with GA-1. Brain Dev 37: 546-551, 2015.

17. Abdul Wahab SA, Yakob Y, Abdul Azize NA, Md Yunus Z, Huey Yin L, Mohd Khalid MK and Lock Hock N: Clinical and mutational analysis of the GCDH gene in Malaysian patients with glutaric aciduria type 1. Biomed Res Int 2016: 1-5, 2016.

18. Boy N, Heringer J, Haege G, Glahn EM, Hoffmann GF Garbade SF, Kölker S and Burgard P: A cross-sectional controlled developmental study of neuropsychological functions in patients with glutaric aciduria type I. Orphanet J Rare Dis 10: 163, 2015.

19. Zhang Y, Li H, Ma R, Mei Li, Wei X, Liang D and Wu L: Clinical and molecular investigation in Chinese patients with glutaric aciduria type I. Clin Chim Acta 453: 75-79, 2016. 
20. Afroze B and Yunus ZM: Glutaric aciduria type 1-importance of early diagnosis and treatment. J Pak Med Assoc 64: 593-595, 2014.

21. Harting I, Boy N, Heringer J, Seitz A, Bendszus M, Pouwels PJ and Kölker S: (1)H-MRS in glutaric aciduria type 1: Impact of biochemical phenotype and age on the cerebral accumulation of neurotoxic metabolites. J Inherit Metab Dis 38: 829-838, 2015.

22. Nunes J, Loureiro S, Carvalho S, Pais RP, Alfaiate C, Faria A, Garcia P and Diogo L: Brain MRI findings as an important diagnostic clue in glutaric aciduria type 1. Neuroradiol J 26: 155-161, 2013.

23. Jiang M, Liu L, Mei H, Li X, Cheng J and Cai Y: Detection of inborn errors of metabolism using GC-MS: Over 3 years of experience in southern China. J Pediatr Endocrinol Metab 28: 375-380, 2015.

24. Pfeil J, Listl S, Hoffmann GF, Kölker S, Lindner M and Burgard P: Newborn screening by tandem mass spectrometry for glutaric aciduria type 1: A cost-effectiveness analysis. Orphanet J Rare Dis 8: 167, 2013.
25. Teng WN, Lin SM, Niu DM, Kuo YM, Chan KH and Sung CS: Anesthetic management of comprehensive dental restoration in a child with glutaric aciduria type 1 using volatile sevoflurane. J Chin Med Assoc 77: 548-551, 2014.

26. Strauss KA, Puffenberger EG, Robinson DL and Morton DH: Type I glutaric aciduria, part 1: Natural history of 77 patients. Am J Med Genet C Semin Med Genet 121C: 38-52, 2003.

27. Vester MEM, Bilo RAC, Karst WA, Daams JG, Duijst WLJM and van Rijn RR: Subdural hematomas: glutaric aciduria type 1 or abusive head trauma? A systematic review. Forensic Sci Med Pathol 1: 405-415, 2015. 